\title{
Implic-arte: arte, tecnología en tiempus de pandemia
}

Paola Andrea Bacca Pachón ${ }^{\star}$

José Miguel Bacca Pachón ${ }^{\star *}$

Olga Lucia Briceño Sandoval ${ }^{* \star *}$ 


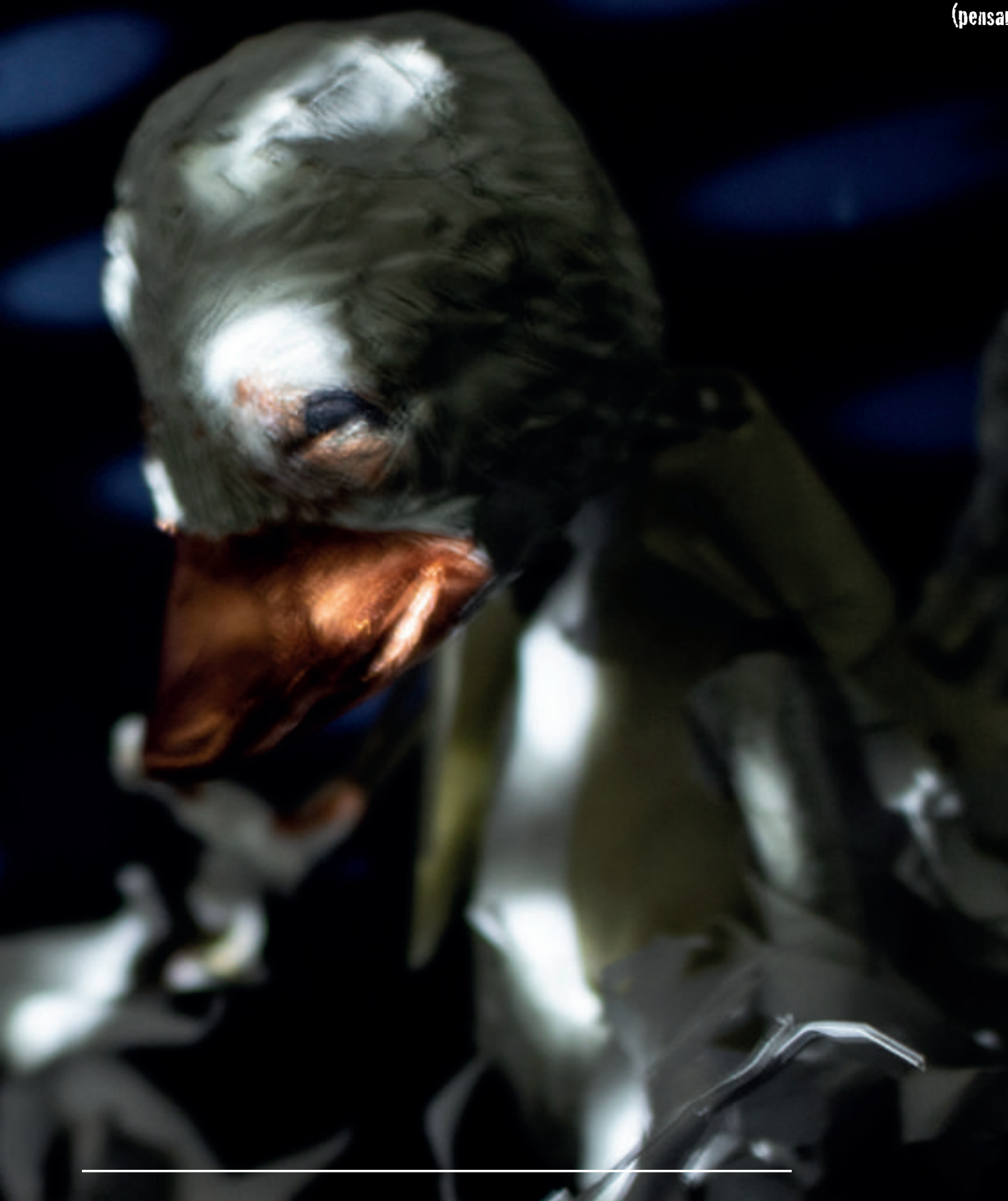

* Máster en Mercadeo del arte, Universidad Antonio Nebrija, España. Docente del Campus Virtual Universidad de Santander (CV-UDES), Colombia. Correo electrónico: paola.bacca@ cvudes.edu.co. Orcid: orcid.org/0000-0002-3665-6939

** Candidato a doctorado en Educación, Universidad de Baja California, México. Docente del colegio Gabriel García Márquez. Director de proyectos de investigación y docente evaluador para el Campus Virtual Universidad de Santander (CV-UDES), Colombia. Correo electrónico: jose.bacca@cvudes.edu.co. Orcid: orcid.org/0000-0003-2947-1263

*** Magíster en Ciencias de la educación, Universidad San Buenaventura, Colombia. Docente del colegio Andrés Bello. Directora de proyectos de investigación y docente evaluadora para el Campus Virtual Universidad de Santander (Cv-UDEs), Colombia. Correo electrónico: olga. briceño@cvudes.edu.co. Orcid: https://orcid.org/0000-0003-1176-2791 


\title{
Resumen
}

En el contexto pedagógico, new media hace referencia a la relación entre el arte y la tecnología, por tanto, identificar las prácticas pedagógicas de los docentes de educación artística que utilizan elementos de new media en los procesos de aprendizaje es el eje central de esta investigación. En ese sentido, en este artículo de investigación se buscó indagar sobre cómo los new media o el arte de los nuevos medios tienen incidencia en los procesos pedagógicos, tomando como base a profesionales de la educación que estuvieran vinculados en el desarrollo de la asignatura de educación artística. Se utilizó el enfoque cuantitativo con metodología descriptiva, abarcando tres categorías: new media, new media y currículo e interdisciplinariedad y transdisciplinariedad, implementando un instrumento para realizar una indagación a 147 docentes de la ciudad de Bogotá. La investigación arrojó que el docente del área de educación artística, desde su interdisciplinariedad curricular y praxis pedagógica, efectúa procesos pedagógicos de incidencia en la enseñanza aprendizaje, pero es necesario que se reelaboren constructos teóricos en relación con la implementación de new media como eje dinamizador en la resolución de problemas en ese proceso y más aún cuando el estudiante necesita fortalecer su proceso creativo en tiempos en los que la socialización e intercambio de experiencias pasa a un segundo plano debido a la presencia del covid-19. Así mismo, se evidenció la ausencia de un equipo docente de educación artística para niveles iniciales, la falta de actualización de los lineamientos de educación artística y orientaciones pedagógicas que incluyan los new media como parte del proceso creativo, sensitivo y estético del estudiante.

Palabras clave: educación artística; tecnología de la educación; medios de enseñanza; investigación educativa; perfeccionamiento de profesores

\section{Implic-Arte: Art and Technology in Pandemic Times}

\begin{abstract}
In the pedagogical scenario, new media refers to the relationship between art and technology. Therefore, identifying the pedagogical practices of teachers of arts education who utilize new media elements in the learning process is the central axis of this research. In this regard, this research article aimed at investigating how The New Media (or New Media Art) had an impact on pedagogical processes considering education professionals who were involved in guiding the subject of artistic education. A descriptive methodology with quantitative approach was used, covering three categories: New media, New media and Curriculum, and Interdisciplinarity and Transdisciplinarity, through implementing an instrument provided to 147 teachers in the city of Bogotá. The research revealed that the teachers of arts education carry out pedagogical processes with an effect on the teaching-learning experience based on their own curricular interdisciplinarity and pedagogical praxis. However, it is necessary to rebuild theoretical constructs in terms of the implementation of The New Media as a dynamic axis to solve problems throughout those pedagogical processes, which becomes even more relevant when the students need to strengthen their creative process in a time when socialization and the exchange of experiences take second place due to the presence of covid-19. Likewise, the shortage of teaching staff for artistic education in basic levels, the inadequate updating of guidelines on artistic education, and the absence of pedagogical suggestions that include new media as a component of the student's creative, sensitive, and aesthetic process were evident.
\end{abstract}

Key words: artistic education; education technology; teaching methods; educational research; upgrading of teachers' skills

\section{Implic-arte: arte e tecnologia em tempos de pandemia}

\section{Resumo}

No contexto pedagógico, novas mídias referem-se à relação entre arte e tecnologia, portanto, identificar as práticas pedagógicas dos professores de arte-educação que utilizam elementos das novas mídias nos processos de aprendizagem é o eixo central desta pesquisa. Nesse sentido, este artigo de pesquisa buscou investigar como as novas mídias ou a arte das novas mídias impactam os processos pedagógicos, tomando como base os profissionais da educação que estiveram vinculados ao desenvolvimento da aula de educação artística. Utilizou-se a abordagem quantitativa com metodologia descritiva, abrangendo três categorias: novas mídias, novas mídias e currículo, e interdisciplinaridade e transdisciplinaridade, implementando um instrumento para realização de inquérito a 147 professores da cidade de Bogotá. A pesquisa mostrou que o professor da área de arte-educação, a partir de sua interdisciplinaridade curricular e práxis pedagógica, realiza processos pedagógicos de incidência no ensino-aprendizagem, mas é necessário que construtos teóricos sejam reelaborados em relação à implementação das novas mídias como eixo dinâmico na resolução de problemas nesse processo e ainda mais quando o aluno precisa fortalecer seu processo criativo em momentos em que a socialização e a troca de experiências ficam em segundo plano devido à presença do covid-19. Da mesma forma, constatou-se a ausência de uma equipe docente de educação artística para os níveis iniciais, a falta de atualização das diretrizes de formação artística e orientações pedagógicas que incluam as novas mídias no processo criativo, sensível e estético do aluno.

Palavras-chave: educação artística; tecnologia educacional; material didáctico; investigação educacional; aperfeiçoamento de professores 


\section{Introducción}

\section{Concepciones sobre new media y educación artística}

El término new media (nuevos medios) hace referencia a una manifestación artística que nació en la década de 1960 con el fin de describir modelos digitales que hicieron parte de la creación de una obra de arte. Al respecto, Fernández (2014) afirma que en 1968 Jasia Reichardt organizó Cybernetic Serendipity en el Institute of Contemporary Arts de Londres, un referente para la tecnocultura, en el que participaron artistas de la talla de Nam June Paik y gurús de la cibernética, como Gordon Pask y Edward Ihnatowicz, entre otros. En ese mismo año fue exhibida en el Museum of Modern Art (мома) la revolucionaria "The Machine as Seen at the End of the Mechanical Age", un proyecto de Pontus Hultén, en el que se exponía la relación entre el hombre y la máquina desde una perspectiva abrumadoramente innovadora.

Ahora bien, aterrizando este término en el contexto pedagógico, new media hace referencia a la relación entre el arte, la tecnología y cómo a partir de allí esta manifestación artística puede ser de gran ayuda para el quehacer pedagógico del docente En este sentido, las nuevas manifestaciones artísticas se convierten en herramientas de comunicación y evolución constante que hace más de una década se vienen vinculando a la práctica docente a través de recursos tecnológicos para hacer que las clases sean innovadoras y reflexivas, generando en los estudiantes nuevos modelos de aprendizaje en cada uno de sus procesos académicos.

En Colombia se fortalecen modelos pedagógicos que han estado presentes, pero también se dan a conocer nuevas miradas desde otras áreas académicas, como lo son la educación artística y específicamente los new media o arte de los nuevos medios. Entender estos procesos hace parte de la formación docente, más aún, la comprensión de que este tipo de lenguajes artísticos hacen parte de la cultura y de la educación, ya que se constituyen en un aporte a la sociedad en general.

Así como la cultura y la sociedad evolucionan, la ciencia, la tecnología y la educación también lo hacen. Desde esta postura, se hace necesario proponer innovadoras prácticas pedagógicas que generen aprendizajes y un nuevo conocimiento dentro del aula escolar, promoviendo una educación de calidad; más ahora, en tiempos en que la educación debe seguir siendo una prioridad, pero en ambientes de aprendizajes diversos y en condiciones sociales adversas. La pandemia obliga al docente a indagar nuevas tecnologías digitales que sean llamativas para el estudiante y su proceso de aprendizaje y que permitan desarrollar y fortalecer procesos creativos desde casa, a través de un computador, una tableta o un celular. Es por ello que, dentro de la ciencia, la educación y la tecnológica se encuentran los new media, una expresión artística que está en constante evolución gracias a herramientas tecnológicas. Su utilidad ha permitido que manifestaciones como las instalaciones, ${ }^{1}$ el video $\operatorname{arte}^{2}$ o el mapping ${ }^{3}$ se enfoquen en propuestas que aporten a un nuevo conocimiento y nuevas maneras de aprender.

Para entender un poco el tema de la educación en el contexto colombiano es necesario precisar que este componente está articulado con la Constitución Política Nacional, la Ley general de Educación y los lineamientos que se crean a medida que se va cambiando de administración o dependiendo las necesidades del contexto. Cada asignatura que se imparte en las instituciones

\footnotetext{
1 Las instalaciones surgen alrededor de 1950 y hacen referencia a espacios que son intervenidos por determinado tiempo a través de las artes plásticas, visuales o el arte sonoro con ayuda de medios electrónicos que sirven como herramienta para comunicar lo que el mensaje del artista.

2 El video arte nace en la década de los 60 y busca expresar, por medio de recursos tecnológicos, propuestas artísticas con alguna temática específica. Algunas pueden contener diálogos o simplemente imágenes en una secuencia determinada.

3 El mapping se desarrolla a partir de proyecciones audiovisuales sobre una superficie y, dependiendo de la intensión del artista, puede acompañarse de movimientos corporales o poesía.
} 
educativas va ligada a planes de estudio y currículos con los cuales se busca aportar a una educación de calidad y, de esta manera, desarrollar en los estudiantes destrezas, habilidades, competencias, procesos creativos y pensamiento crítico que les sean útiles a futuro para su formación profesional.

Por lo anterior, la educación incorpora en la práctica elementos tecnológicos que acompañan el proceso de aprendizaje de los estudiantes y que se convierten en elemento fundamental para el docente. Para llegar a ello, existe el currículo que para el Ministerio de Educación Nacional de Colombia hace referencia al conjunto de criterios, planes de estudio, programas, metodologías y procesos que contribuyen a la formación integral, a la construcción de la identidad cultural nacional, regional y local, incluyendo también los recursos humanos, académicos y físicos, para poner en práctica las políticas y llevar a cabo el proyecto educativo institucional (Ministerio de Educación Nacional, s.f.).

Por su parte, para el Ministerio de Cultura de Colombia, la educación artística se define como:

Un campo estratégico para la formulación e implementación de políticas públicas que permitan incluir los diversos niveles y modalidades de la educación en arte de acuerdo a la competencia que le otorga la Ley General de Cultura. En este desempeño, el principal aliado es el Ministerio de Educación Nacional. (Ministerio de Cultura, 2018, párr. 1)

Teniendo en cuenta lo anteriormente descrito, resulta claro que dentro de una educación de calidad es necesario vincular procesos culturales y ambientes de aprendizaje que conduzcan a nuevos escenarios educativos y reflexivos, tanto para el docente como para el estudiante. Es así como el currículo se establece como un elemento fundamental, ya que es el punto en el cual se entrelazan todos componentes necesarios para lograr una formación integral y llegar a tener una educación de calidad.

Para el caso de la educación artística - asignatura de obligatorio desarrollo en las instituciones escolares del país-, el currículo se apoya en los Lineamientos de la educación artística y el documento número 16 de orientaciones pedagógicas desarrollado del Ministerio de Educación Nacional, bajo el cual, en el año 2010, se propusieron tres dimensiones que articulan tres procesos fundamentales representados a continuación:

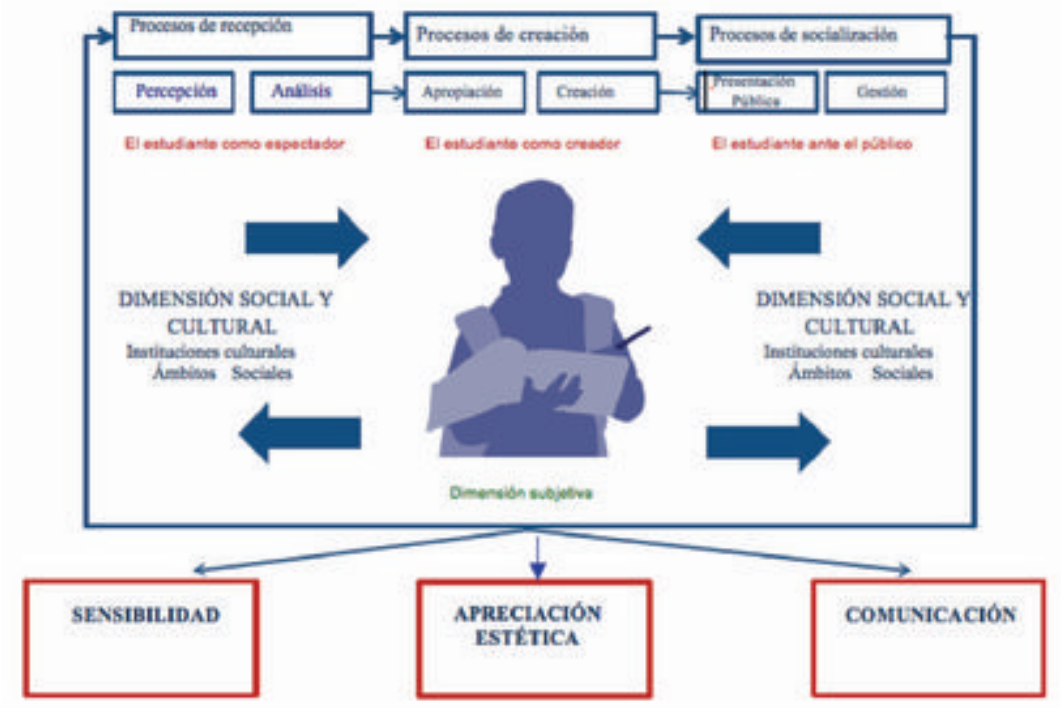

Figura 1. Orientaciones pedagógicas para la educación artística en básica y media. Fuente: Ministerio de Educación Nacional (2010). 
Estas tres dimensiones, al trabajarlas en conjunto, logran desarrollar y fortalecer procesos creativos en los estudiantes y aportar a una educación integral. Esto permite comprender que la educación debe partir de una integración curricular de diversas áreas del conocimiento y en ese sentido es necesario en primer lugar establecer sus bases conceptuales. Para Arévalo et ál. (2016), el Ministerio de Educación en Colombia propone elementos y criterios curriculares que tienen como fin integrar las Tecnológicas de la Información y la Comunicación (TIC) a las diversas áreas del conocimiento, con propósitos no solo académicos sino culturales y políticos. Al respecto, se hace necesario para el caso de la educación artística vincular tecnologías educativas que aporten a la formación integral y que apoye las demás asignaturas escolares.

Dentro de esas didácticas tecnológicas se podría hacer un recorrido en relación con términos taxonómicos que ayude a identificar las prácticas artísticas vinculadas a la educación, el arte y la tecnología (arte fax, arte electrónico, arte digital, software art, videoarte, instalaciones, etc.). Sin embargo, más allá de ello, es importante entender que estas manifestaciones artísticas pueden estar inmersas en un currículo y un plan de estudios como apoyo, no solo en la formación docente, también en la práctica educativa.

De lograrse integrar estas expresiones artísticas, las TIC junto con el currículo se convierten en ejes principales para el diseño de nuevos ambientes de aprendizajes que aportan al quehacer pedagógico del docente. Asimismo, en el proceso de enseñanza aprendizaje que se desarrolla en el contexto educativo, el docente los aplica en su labor teniendo en cuenta las características de sus estudiantes. Esto quiere decir que el arte y la tecnología podrían apoyar aprendizajes que motiven al estudiante a indagar en sus propios procesos, pensamientos, sensaciones y emociones que pueden ser abordadas y desarrolladas en ejercicios artísticos tecnológicos e innovadores.

La relación del currículo y la enseñanza de la educación artística en los niveles de formación es de gran relevancia para una educación integral y más aún si van de la mano de competencias que apoyen los procesos en cada nivel de escolaridad. En este sentido,
Rocha (2016) sostiene que las competencias, desde las más complejas a las más simples, toman como punto de partida algunos elementos que le van a permitir clasificarlas en lo noonico (epistémico), las potencialidades (habilidades), lo personal (su desarrollo), lo grupal (relación inter o intrapersonal) y lo social (contexto, cultura). Lo anterior, aterrizado al contexto educativo, es aquello que necesitan los estudiantes para lograr un óptimo aprendizaje.

En consecuencia, es posible entender que los new media aparte de una manifestación artística, pueden ser una herramienta didáctica en la que se integre la tecnología y el arte. Esto obedece a la necesidad de estar en constante cambio e innovación dentro del aula escolar y, por ende, la posibilidad de fortalecer el quehacer pedagógico docente. Asignaturas como la educación artística deben apuntar a la innovación sin perder procesos creativos y estéticos fundamentales en la formación del estudiante. La pandemia por la que atraviesa el país en la actualidad obliga a replantear didácticas educativas que ayuden en procesos formativos en los cuales el hogar del estudiante se convierte en el nuevo salón de clase y por tanto su ambiente de aprendizaje está supeditado a la tecnología.

\section{La interdisciplinariedad y la transdisciplina- riedad: una clave para la educación de calidad}

El concepto interdisciplinariedad implica un grado de compromiso y conciencia en términos de calidad educativa, aprendizaje innovador y competencias para la vida. Según el estudio de Sclater y Lally (2018), entender la interdisciplinariedad en contextos como el arte, la pedagogía y la tecnología implica un proceso continuo que permite crear experiencias y entornos de aprendizaje imaginativos y abiertos que apoyen el desarrollo de múltiples posibilidades de aprendizaje potencial entre una amplia gama de estudiantes.

En concordancia con ello es pertinente hablar de modelos educativos que contribuyan a la innovación del aprendizaje potencial y, para el caso de esta investigación, el aporte que hacen los recursos tecnológicos al quehacer pedagógico del docente, dado que ayudan de manera significativa a lograr ambientes propicios que se enriquecen con las otras áreas académicas. 
$\mathrm{Al}$ respecto, González (2016) invita a una toma de conciencia frente a la manera como se debe comprender y reaprender la educación artística. Propone elementos como la autodeterminación y la autoeducación expandida; palabras que pueden sonar confusas, pero que son claves para que tanto el profesional no licenciado como el docente que desarrolla esta asignatura observen en los new media recursos didácticos que pueden ir más allá de un aula escolar.

Desde esta perspectiva, el papel de la pedagogía se convierte en transversal al proceso interdisciplinario y con los aportes desde el arte, la ciencia y la tecnología, se puede lograr en cada estudiante procesos de aprendizaje adecuados, estructurados y apoyados en teorías, modelos y didácticas innovadoras. En cuanto a la interdisciplinariedad, es necesario observarla desde otros contextos, como la educación superior, ya que conduce tanto al docente como al estudiante a desarrollar procesos trasversales que conlleven al inicio de desarrollos investigativos. Por lo tanto, es un desafío que implica una apertura al cambio y estar en capacidad de modificar posibles estructuras pedagógicas que están inmersas en el currículo.

Por lo anterior, existe un interés particular para el docente al querer profundizar en su área específica de conocimiento y cómo a partir de allí establecer diálogos con otras áreas que enriquezcan tanto el currículo como su metodología de trabajo. Dentro de este campo, Gombrich (2018) propone que la educación superior debería denominarse educación interdisciplinaria, pues es la oportunidad de encontrar similitudes que ayuden a enriquecer el currículo y, en ese sentido, innovar en estrategias didácticas y modelos de evaluación.

La interdisciplinariedad enriquece no solo el aprendizaje sino los procesos investigativos que promueven la generación de nuevo conocimiento. Para el caso de los new media o arte de los nuevos medios, sus diversos recursos tecnológicos han aportado al mejoramiento de prácticas en diversas áreas del conocimiento. Esto queda en evidencia, por ejemplo, en la investigación realizada por Xu et ál. en 2019, en la que a través de recursos tecnológicos fue posible analizar las expresiones del rostro de los estudiantes dentro de su proceso de enseñanza aprendizaje.

Estas relaciones entre las Tic y la educación artística ponen de manifiesto una interdisciplinariedad significativa en campos pedagógicos que son poco conocidos en el sector educativo y que vale la pena destacar, como lo es el patrimonio material e inmaterial, un campo ligado estrechamente con la identidad de un pueblo o nación. En el contexto escolar este tema ha sido abordado de manera general con el apoyo del área de ciencias sociales en las instituciones educativas y, a pesar de ello, en la actualidad no hay suficiente conciencia frente a la importancia de este elemento, cómo impacta la sociedad y, por ende, a la cultura. 
En el sector cultural, y gracias a las Tic, el patrimonio se ha podido visibilizar y se han orientado procesos de preservación y restauración de bienes con el fin de dar a conocer la importancia de salvaguardarlos. Entender la cultura del patrimonio también es hablar de interdisciplinariedad. En ese sentido a través de los new media se han logrado desarrollar propuestas que le permiten a los estudiantes acercarse al patrimonio y de esta manera cumplir con las directrices sobre la salvaguardia del patrimonio cultural inmaterial establecidas por la Unesco (2016). Se podría afirmar que se convierte en un patrimonio "actual y vivo", que está muy relacionado con la mirada de Carmen Gómez-Redondo y su equipo de investigadores, quienes afirman que:

enfocar ambos procesos desde el punto de vista educativo supone un tipo de relación más profunda. Por tanto, entendemos que, para una correcta construcción identitaria en el patrimonio, es necesario patrimonializar para identizar, precisándose una propiedad simbólica del patrimonio, que genere un nuevo referente identitario a nivel individual, que permita posteriormente generar o confluir en una identidad colectiva, una pertenencia real. (Gómez-Redondo et ál., 2016. p. 57)

Una perspectiva complementaria al respecto es la que entregan Llano-Arana et ál. (2016), quienes señalan que la interdisciplinariedad es un término de gran relevancia para el sector educativo, dado que es el punto en el que se conectan las áreas del conocimiento y tiene como propósito aportar al aprendizaje en el aula escolar. Definen entonces la interdisciplinariedad como:

un abordaje pedagógico del proceso docente que se realiza con el propósito de lograr objetivos generales relacionados con determinados conocimientos, habilidades y modos de actuación profesional que son clave en su formación y que no es posible lograrlos con la debida profundidad desde la óptica de una sola disciplina o asignatura académica. (2016, p. 32)

Con esto en mente, se comprende que cada asignatura entra en dialogo, identificando y luego proponiendo nuevas didácticas en tecnologías digitales que aporten a una educación de calidad. En la actualidad, los estudiantes están permeados por información que debe ser filtrada en pro de una buena calidad educativa y que debe ir de la mano con elementos de la educación tradicional que han hecho aportes a este contexto y que son utilizados por algunos docentes dentro de su quehacer pedagógico. Experiencias memorísticas, asociativas y de clasificación son apoyadas con recursos tecnológicos en diversas áreas académicas. Utilizar recursos tecnológicos podría ayudar al estudiante a tener confianza en su propio proceso y tener un mayor interés que lo puede llevar al fortalecimiento de su creatividad.

Desde sus múltiples manifestaciones, los new media pueden proporcionar claves para el aprendizaje que se adapten al contexto educativo. Un ejemplo de ello es el arte sonoro, un lenguaje que propone alternativas didácticas que busca fortalecer procesos cognitivos; es una manera en la que los estudiantes pasan del mundo físico a un mundo natural dentro de ambientes de aprendizajes propicios para ello. Este tipo de propuestas muestran una vez más que la interdisciplinariedad enriquece procesos cognitivos musicales en cualquier nivel de escolaridad.

Es pertinente revisar el trabajo que presentan Murillo et ál. (2019 en su artículo titulado "El aula como caja de resonancia para la creación sonora: nuevas arquitecturas y herramientas tecnológicas para acercar el arte sonoro al ámbito educativo", una propuesta que invita al docente a salir del aula tradicional para experimentar, desde recursos tecnológicos, las múltiples posibilidades de desarrollar procesos creativos, apoyar procesos cognitivos y lograr aprendizajes interdisciplinares. Son espacios de creación y co-creación que urge desarrollar en la educación colombiana, ya que se han identificado infinidad de investigaciones en las que se vinculan la educación y la tecnología; sin embargo, es necesario profundizar aún más en enfoques pedagógicos que trasciendan en el aprendizaje y enriquezcan el quehacer pedagógico del docente, sobre todo en áreas tan importantes como la educación artística.

En otro orden de ideas, se tiene que la transdisciplinariedad aborda problemas por medio de la integración de las ciencias, buscando que el proceso de aprendizaje sea más eficaz. Para González-Aguilar (2014), es la manera en la que se puede integrar la realidad sin necesidad de segmentarla; gracias a la interdisciplinariedad, la transdisciplinariedad puede abordar campos relacionados con el ser dentro del campo holístico. A partir de esta postura, 
se corrobora la necesidad que el docente de educación artística explore diversas metodologías, abarcando no solo el conocimiento sino otros elementos fundamentales de la asignatura, como las emociones, las sensaciones y los procesos creativos.

El docente debe proponer metodologías que respondan a la necesidad de los estudiantes y, a su vez, se conviertan en un peldaño para alcanzar los objetivos propuestos en la asignatura desde un proceso formativo integral, es decir, abordándola desde la interdisciplinariedad y la transdisciplinariedad. No obstante, en la actualidad urge tener en cuenta dos miradas: la primera, que obedece a la adopción de un estilo y una forma de apropiación diferentes, relacionados con la enseñanza del docente de educación artística en tiempos de pandemia, cuando el estudiante no cuenta con los recursos necesarios para fortalecer sus procesos con el acompañamiento del docente; la segunda, relacionada con la amplia gama de expresiones artísticas que hacen parte de los new media y que se apoyan en recursos tecnológicos.

Desde esta premisa se hace necesario comprender que la interdisciplinariedad requiere de nuevos esquemas de trabajo colaborativo que permita correlacionar las diversas áreas del conocimiento en las que se desarrollen procesos académicos y reflexivos, consecutivos y evolutivos. Hoy en día cuando el estudiante no puede socializar en un mismo espacio, los modelos de trabajo colaborativo se convierten en herramientas fundamentales que le permiten a los estudiantes, desde su hogar y con ayuda de la tecnología, desarrollar competencias en pro de su formación integral, lo que se convierte en la materialización de un aprendizaje apoyado en la transversalidad.

Con lo expuesto anteriormente se puede identificar todo un espectro de alternativas que son válidas al llevarlas al contexto educativo; sin embargo, esto debe ir a la par con una actualización docente constante e innovadora que sea apoyada por las Tic.

\section{La pedagogía del docente}

La educación induce a la persona a procesos de transformación, contextualización y nuevas formas de conocimiento. Esta evolución sugiere cambios constantes en su cultura, en la responsabilidad social del ciudadano y para el caso del docente, en el contexto educativo, hace que se identifique como un individuo que adquiere un rol en la sociedad que le exige en forma sistemática pensarse como sujeto reflexivo de su quehacer pedagógico. Edelstein, (2015) señala al respecto que la práctica del docente constantemente se ve afectada por adversidades del contexto, que lo obligan a potencializar su conocimiento y revaluar su ejercicio docente, buscando dar respuesta a interrogantes y prejuicios de la sociedad. Su formación y práctica educativa se convierten en experiencias creativas que son documentadas y que a futuro se trasforman en relatos de espacio y tiempo.

Por ello es necesario romper con paradigmas tradicionales, vencer miedos y tomar parte de nuevos desafíos que apunten a responder como eje de desarrollo social, tal como lo refieren Nieva y Martínez, "si el docente no cambia, no podrán hacerse cambios relevantes en los procesos educativos para que estos sean conforme a la necesidad que se genera de las demandas sociales" (2016, p. 16). El docente en su actuar pedagógico es un guía indispensable de procesos que ayuden a generar cambios en pro de una educación de calidad.

Estos cambios empiezan con la didáctica como un elemento esencial en su actuar pedagógico, que es clave para la educación artística y su relación con la tecnología. De Camilloni (2007) afirma que la dinámica social en la que está envuelta la educación hace que surjan didácticas, no solo para todas las áreas del conocimiento, sino también atendiendo a la edad de los estudiantes, al tipo de institución o al nivel de escolaridad.

Surge, entonces, una complejidad, en la medida que el docente en su ejercicio
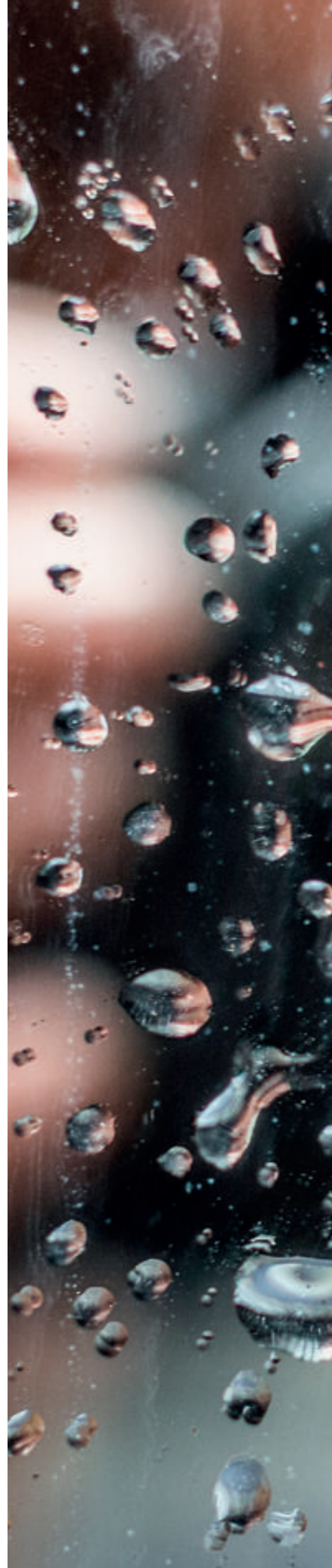

que el docente en su ejercicio 
pedagógico debe replantear sus métodos atendiendo a las características de la población y del área disciplinar que, sin ser un imposible, lo obliga a estar a la vanguardia de las exigencias y retos que impone la sociedad frente a situaciones adversas, como la que atraviesa el mundo por cuenta de la covid-19. Adicionalmente, debe indagar acerca de las posibilidades que brinda el uso de las nuevas tecnologías y lo lleve a un continuo autodescubrimiento como sujeto político, con la posibilidad de cambiar realidades y atender a las transformaciones de la sociedad actual, dado que finalmente gracias a su ejercicio docente la educación se ha convertido en un tejido humano de enseñanza aprendizaje.

Aunque puede ser un proceso difícil para los docentes que desarrollan su ejercicio pedagógico en sitios apartados del casco urbano, para el país es un compromiso y una responsabilidad proporcionar las herramientas para que todos los profesionales de la educación puedan estar a la vanguardia de las nuevas tendencias educativas y de esta manera mejorar su ejercicio docente. Ahora bien, es importante entender que el docente necesita estar a la vanguardia de todos los adelantos que ofrece la tecnología, participar desde el conocimiento en dinámicas pedagógicas para hacer frente a la situación pandémica. El docente es un protagonista que incide en la adecuada formación del hombre que la sociedad actual requiere y esto demanda, por supuesto, un proceso de formación constante y a conciencia, pues los ambientes de aprendizaje cambiaron y la innovación es el eje central.

Es evidente que se necesita un cambio desde diferentes ámbitos de la formación pedagógica (conocimientos, destrezas, habilidades), que debe interiorizar el docente para dar respuesta a escenarios creativos y actuales, como es el caso del uso de las nuevas tecnologías para todas las áreas académicas, incluida la educación artística. Por tanto, es relevante redireccionar este proceso formativo hacia espacios que involucren no solo el conocimiento disciplinar y lo pedagógico, sino que se confiera más atención a la parte artística y tecnológica.

Es por ello que estos ámbitos de la pedagogía están relacionados con la formación por competencias, en la que se propone que el estudiante a partir de la resolución de una problemática desarrolle el conocimiento. Sin embargo, Díaz-Barriga (2011) anota que, aunque competencia es un término relativamente nuevo en el sector educativo, se evidencia una confusión en su uso y esto podría afectar el 
proceso estudiantil, ya que el objetivo de la educación es formar al ser humano y la competencia está orientada a la formación en el campo laboral.

En virtud de ello se puede concluir que el docente de educación artística debe estar en capacidad de direccionar su proceso de enseñanza, de reconocer las características del contexto y sus relaciones, de apropiarse de los cambios que se han suscitado en el arte y, en este caso, desde la evolución de los new media con el fin de aplicar estrategias pedagógicas actuales que permitan didácticas innovadoras como posibilidad de construcción de sujetos. Desde esa postura, el docente se convierte en un actor que trasforma y se trasforma a sí mismo (Martín, 2015).

Como proceso pedagógico, el aprendizaje significativo explica la manera en la que el individuo le da sentido al conocimiento nuevo al crear conexión con su esquema cognitivo; así, las ideas previas que tiene un estudiante cobran sentido, ayudan a desintegrar representaciones y a entrever nuevas formas de interacción entre ellas. Desde esta perspectiva, el docente asume una postura mediadora y propicia un aprendizaje para que el estudiante potencie su capacidad de análisis, se reconozca como ser crítico y se empodere como sujeto propositivo.

El docente se ha destacado por presentar el contenido de una manera didáctica utilizando las herramientas según el momento histórico en el que se encuentra, pero con los cambios que la sociedad del conocimiento ha generado en los espacios académicos se ve en la necesidad de transformar su práctica pedagógica, dado el hecho que los estudiantes de hoy conviven en escenarios digitalizados. La tecnología abre un abanico de posibilidades que pretende, entre otros, permitir al docente crear ambientes de aprendizaje con una intencionalidad clara y con base en conocimientos de una o de varias disciplinas. Claramente se evidencia la interrelación constructivista y la necesidad de crear ambientes de aprendizaje adecuados en los escenarios digitalizados para la apropiación del conocimiento por parte del estudiante, lo cual desafía cognitivamente al docente.

Al respecto, Torres-Cañizález y Cobo-Beltrán sostienen que "la tecnología educativa debe garantizar que las experiencias de aprendizaje se configuren basándose en los principios de la globalización, la interdisciplinariedad y transdisciplinariedad, empleando acciones que se derivan del aprendizaje experiencial, por descubrimiento, por proyectos y por problemas" (2017, p. 36).
De tal manera, es importante asumir las competencias como un engranaje que incluye la articulación del currículo, el perfil de profesional que se pretende formar, el contexto cultural y social del país. En estos dos últimos aspectos es en los que urge un cambio de mentalidad del docente, que en palabras de Zabalza-Beraza (2012) debe comprender que la formación por competencias hace parte del quehacer pedagógico, como un ejercicio que debe desarrollarse a profundidad en las instituciones de educación superior y que en el ejercicio laboral el docente debe ser apropiado y puesto en práctica en el aula escolar de la mano de la tecnología.

Es, por tanto, un deber de las universidades estar a la vanguardia en sus currículos académicos y sus planes de estudio, ofreciendo una amplia oferta que esté directamente relacionada con su campo profesional, que para esta investigación es la educación artística y todo lo que ella encierra. Ahora bien, la tecnológica ya cuenta con variedad de alternativas que desde los new media deben darse a conocer y permitir su uso como recurso didáctico dentro del aula escolar, lo que apunta directamente a una educación de calidad.

El rol del docente cambia y lo lleva a escenarios donde se le reconoce como mediador, orientador y tutor; por lo mismo, da la oportunidad de crear ambientes contextualizados, que favorecen la apropiación de los medios digitales en su quehacer diario como parte de su formación profesional. Lo anterior invita al docente a implementar las tecnologías teniendo en cuenta las características de sus estudiantes y dar solución a problemas en el ámbito pedagógico, con base en objetivos, metodologías, modelos, técnicas, currículo, didácticas, ambientes de aprendizaje, teorías y prácticas orientadas a procesos de enseñanza aprendizaje con pertinencia y sentido.

\section{Metodología}

La presente investigación se desarrolló bajo un enfoque metodológico descriptivo, ya que se buscó identificar las características más comunes entre los docentes de educación artística, indagando sobre la aproximación o aplicación que ellos tienen con relación a los elementos vinculados con los new media en los procesos de enseñanza-aprendizaje. Este enfoque permite resaltar las características más comunes que se encuentran en la población estudio, pero sin tener en cuenta aspectos como edad, sexo, espectro laboral o especialidad de las artes. 
Hernández-Sampieri y Mendoza-Torres (2018) definen las variables como aquellas que se pueden aplicar a personas, objetos, hechos y fenómenos, los cuales adquieren valor en relación a la variable referida. Para esta investigación la variable a tener en cuenta es los new media y su posible aplicación dentro de la práctica educativa. Se recolectó información de manera individual, pero en el marco de una tipología de docentes licenciados que dictan el área de educación artística y se encuentren vinculados a alguna institución educativa en la ciudad de Bogotá, Colombia. Para ello, se diseñó y aplicó un instrumento online ${ }^{4}$ bajo tres categorías:

1. New media

2. New media y currículo

3. Interdisciplinariedad y transdisciplinariedad

Cada categoría se articulaba alrededor de cinco preguntas y el docente debía seleccionar la que considerara correcta.

Para esta investigación se identificaron dos factores principales que influyeron en la definición de la metodología a aplicar:

a. Conocimiento actual del tema de investigación que revele la revisión bibliográfica: el primer referente que da inicio a la investigación es la inquietud que nace de la experiencia como directores de investigación y evaluadores del campus virtual CV-UDEs de la Universidad de Santander al concluir la falencia existente en relación a la falta de investigaciones e información sobre la articulación o transversalización de los elementos de new media en el área de educación artística. En el desarrollo de los estados del arte y marcos teóricos que soportan las investigaciones que se han dirigido en esta universidad existen pocos documentos o literatura que aporte, indique o explore la articulación de estos elementos en dentro del quehacer pedagógico en Colombia.

b. La perspectiva que los investigadores pretendieron dar al estudio: con base en las especialidades y experiencia docente de los autores de esta investigación, se realizó un primer acercamiento de manera descriptiva para caracterizar el fenómeno de la implementación de new media en los procesos de enseñanza aprendizaje en los estudiantes. Finalmente se parte de un tipo de estudio cuantitativo por su rigurosidad y sistematización de la información recopilada que permite orientar la pregunta: ¿el docente tiene elementos o bases académicas enfocadas en los new media para potencializar su praxis pedagógica en los procesos de aprendizaje?

\section{Enfoque cuantitativo como base de la metodología descriptiva}

La investigación toma como eje fundamental los planteamientos de Hernández-Sampieri y Mendoza-Torres (2018) para la visualización de los pasos a seguir, así como la trazabilidad de la misma. Sin embargo, para resaltar la importancia del enfoque cuantitativo en la metodología descriptiva se realizó un paralelo entre tres trabajos, ejercicio que fue necesario construir para tener mayor claridad y certeza frente al propósito investigativo.

4 Enlace del instrumento: https://cutt.ly/7hpBO46 
Tabla 1. Paralelo del enfoque cuantitativo en la metodología descriptiva

\begin{tabular}{|c|c|c|}
\hline Autores & Propósito & Funciones \\
\hline $\begin{array}{l}\text { Gómez } \\
\text { (2015) }\end{array}$ & $\begin{array}{l}\text { Determinar o describir cómo son los } \\
\text { hechos o conceptos relevantes del } \\
\text { fenómeno investigado. }\end{array}$ & $\begin{array}{l}\text { Describir } \\
\text { detalladamente } \\
\text { eventos, hechos y } \\
\text { situaciones. }\end{array}$ \\
\hline $\begin{array}{l}\text { Mousalli- } \\
\text { Kayat (2015) }\end{array}$ & $\begin{array}{l}\text { Especificar las propiedades, las } \\
\text { características y los perfiles de personas, } \\
\text { grupos, comunidades, procesos, } \\
\text { objetos o cualquier otro fenómeno que } \\
\text { se somete a un análisis. Únicamente } \\
\text { pretenden medir o recoger información } \\
\text { de manera independiente o conjunta de } \\
\text { las variables. }\end{array}$ & $\begin{array}{l}\text { Describir el } \\
\text { desarrollo, avance o } \\
\text { cambio de un evento } \\
\text { a lo largo del tiempo. } \\
\text { Identificar y clasificar } \\
\text { eventos en un } \\
\text { contexto. }\end{array}$ \\
\hline $\begin{array}{l}\text { Hernández- } \\
\text { Sampieri y } \\
\text { Mendoza- } \\
\text { Torres (2018) }\end{array}$ & $\begin{array}{l}\text { Especificar las propiedades, } \\
\text { características y perfiles de personas, } \\
\text { grupos, comunidades, procesos, objetos } \\
\text { o cualquier otro fenómeno que se } \\
\text { someta a un análisis. Miden o recolectan } \\
\text { datos y reportan información sobre } \\
\text { diversos conceptos, variables, aspectos } \\
\text { del fenómeno a investigar. }\end{array}$ & $\begin{array}{l}\text { Medir fenómenos o } \\
\text { variables para estimar } \\
\text { su ocurrencia o } \\
\text { magnitud. Mostrar } \\
\text { con precisión } \\
\text { dimensiones de un } \\
\text { fenómeno, hecho o } \\
\text { caso. }\end{array}$ \\
\hline
\end{tabular}

Fuente: elaboración propia.

\section{Muestreo}

Se tomó como base del estudio a la población docente que fue estudiante de maestría del Campus Virtual cv-udes de la Universidad de Santander y las Direcciones Locales de Educación de las localidades de Bogotá. Es importante aclarar que la investigación estuvo sujeta a la cantidad de docentes que dictan dicha asignatura en las instituciones, es decir, que se tuvo en cuenta si el número poblacional estuvo acorde con los datos necesarios para recopilar información.

Para Hernández-Sampieri y Mendoza-Torres (2018) existen dos grandes tipos de muestra: las muestras probabilísticas y no probabilísticas. En las primeras, todos los elementos de la población tienen la misma probabilidad de ser escogidos y se obtienen definiendo las características de la población y el tamaño de la muestra. En este caso, el instrumento llegó a 831 docentes, siendo esta la muestra probabilística y cumpliendo con la característica del estudio al tener éxito en 141 docentes dentro del rango (docentes que están dictando la asignatura de educación artística en instituciones educativas de la ciudad de Bogotá) para la continuidad en la aplicación del instrumento; de esta manera, se estableció que la muestra es aplicable al lograr el muestreo proporcional, pues no se limitó el envío del instrumento para que todos los docentes tuviesen la oportunidad de ser seleccionados.

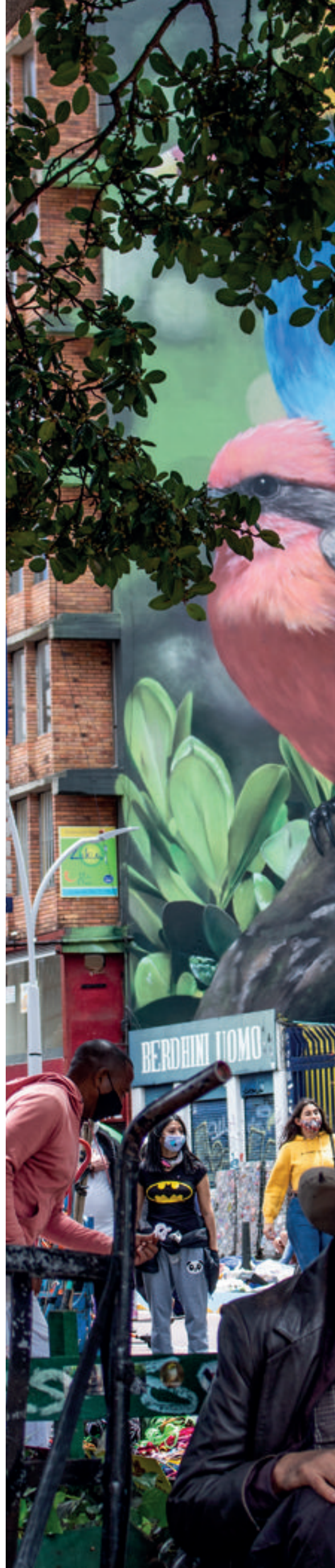




\section{Cálculo del tamaño de la muestra}

En la investigación cuantitativa es necesario tener claro el nivel de confiabilidad estadístico de la muestra, así como el error máximo que se desea asumir. Para esta investigación se realizó el cálculo de muestra con software decisión Analyst sTATs ${ }^{\mathrm{TM}} 2.0$, sugerido por HernándezSampieri y Mendoza-Torres (2018).

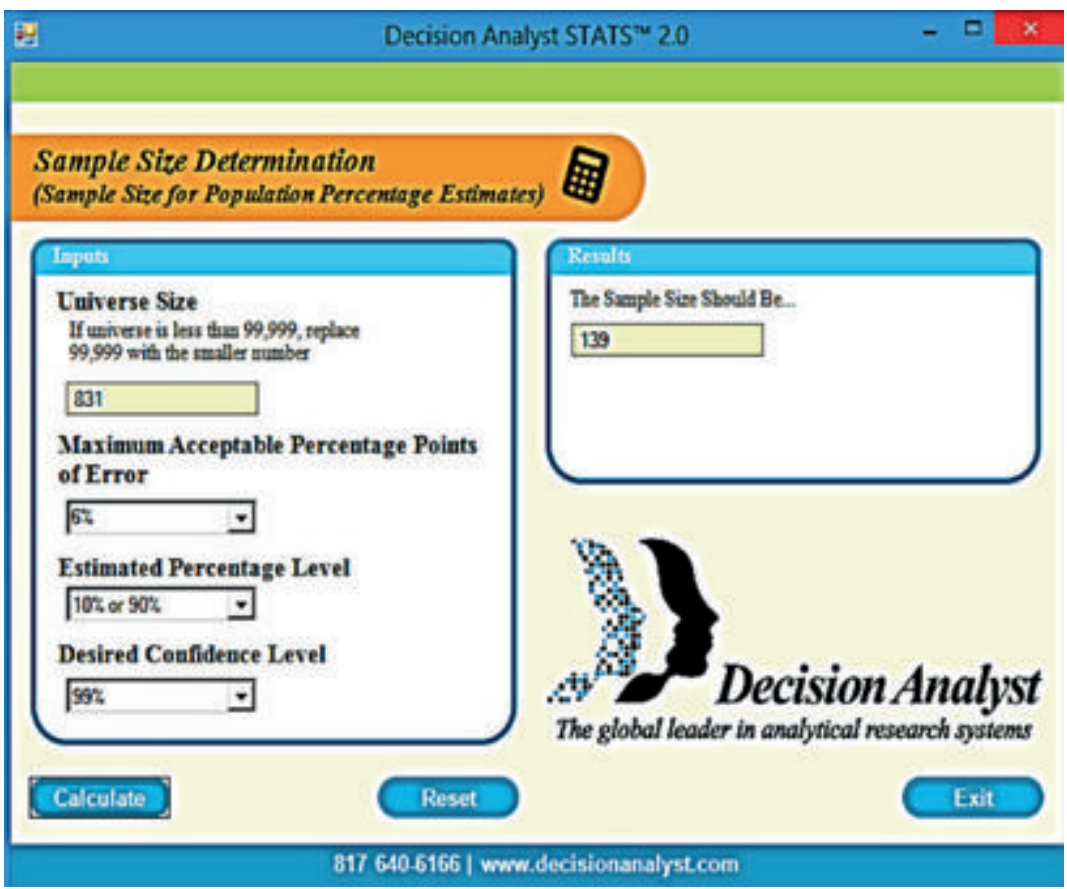

Figura 2. Calculo de la muestra utilizando el software Analyst STATSTM 2.0.

Fuente: elaboración propia.

\section{Población}

Fueron 831 docentes, teniendo en cuenta el cálculo de la muestra realizado en el software y se encuentra dentro de los rangos aceptables positivos al tener como número de muestra 141 docentes de la ciudad de Bogotá que dictan la asignatura de educación artística.

Es importante anotar que en el proceso de recolección de información fue vital centrar los tipos de medición que se pudiesen implementar de los cuatro existentes (nominal, ordinal, intervalo y razón), para este caso se utilizaron las siguientes:

- Nominal: docentes de LEA (Licenciatura en Educación Artística); MAP (Maestros en Artes Plásticas); MAV (Maestros en Artes Visuales); ARQ (Arquitectos); DIs (Diseñadores gráficos).

- Ordinal: se incorporó un valor numérico para lograr la visualización de los datos de manera gráfica.

Para la visualización de los datos se utilizó el software SigmatPlot, enfocado a la visualización de gráficos de grandes muestras de carácter cuantitativo, algunas características el análisis de datos en diferentes pruebas $t$, regresiones lineales, regresiones no lineales y Anova con facilidad, compatible $100 \%$ para importar datos Microsoft Excel y regresión para ajustar los datos de manera fácil y precisa. 


\section{Resultados}

Para poder analizar los hallazgos encontrados se hace necesario dar a conocer la tipología presentada en las gráficas. Las series hacen referencia a los docentes que desarrollaron el instrumento y corresponde a la tipología "E". Cuando se habla de serie 1, 2, 3, 4, 5 son las respuestas que arrojaron los docentes en cada una de las tres categorías que permitieron abarcar aquellos elementos que son importantes dentro del ejercicio docente y que son pertinentes a analizar.

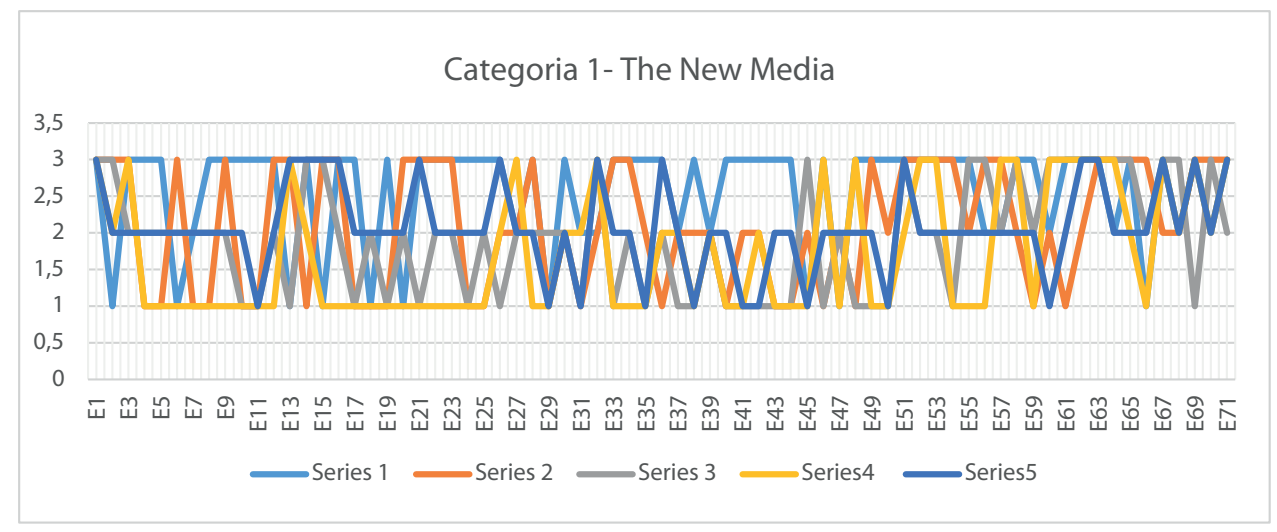

Figura 3. New media o arte de los nuevos medios

Fuente: elaboración propia.

La serie 1 permite identificar que los docentes tienen conocimiento en relación a las expresiones artísticas que son creadas a partir de recursos tecnológicos. Se logra equiparar una constante frente a lo que significa new media y a qué hace referencia este término. Esto permite concluir que el docente está a la vanguardia de nuevas propuestas relacionadas con el arte y la tecnología. Algunas de estas manifestaciones artísticas se encuentran en museos o centros de arte y cultura alrededor del mundo, a los que el docente puede acceder desde la web. Los docentes logran comprender que a través de esta nueva manifestación artística adquieren un conocimiento que aporta a su quehacer pedagógico y es allí donde se pueden originar nuevas metodologías de enseñanza dentro del aula escolar, en las cuales el arte y la tecnología puedan aportar al proceso de aprendizaje.

Caeiro y Muñiz (2019) señalan que los procesos de aprendizaje de los estudiantes en el área artística pueden verse fortalecidos desde estructuras o alternativas didácticas en las que se involucren lo científico y lo tecnológico. Estos procesos cognitivos y visuales deben desarrollarse desde los primeros años de escolaridad. Lo expuesto anteriormente abre un abanico de posibilidades para innovar la práctica educativa en un área académica en la cual las sensaciones, las emociones, la apreciación estética y los procesos creativos son los primeros insumos para el aprendizaje.

En la serie 2 los docentes identifican posibilidades dentro de la práctica pedagógica frente a la definición de new media y señalan dos oportunidades: la primera consiste en desarrollar propuestas entre el arte la ciencia y la tecnológica; y la segunda se entiende como una nueva manera para que el estudiante explore, analice nuevas formas de expresión y los beneficios que puede otorgar esta. Estas dos miradas lo que permiten concluir en realidad es que el docente sí puede recurrir a los new media como recurso didáctico en la medida que se fortalezcan las competencias propias de dicha asignatura y desarrollen procesos bajo las orientaciones pedagógicas del documento estipulado por el Ministerio de Educación Nacional relacionadas con la sensibilidad, la comunicación y la apreciación estética. En efecto, tanto el arte como la tecnología son elementos fundamentales dentro del proceso de aprendizaje. Más allá de impartir conocimiento se busca que los estudiantes adquieran las herramientas necesarias para continuar en su paso a la universidad. 
En otro sentido, la serie 3 no arroja constantes frente a la respuesta. Por el contrario, se logra identificar que para los docentes los new media aportan en el desarrollo de la creatividad del estudiante y a su vez esta manifestación artística enriquece otras asignaturas de igual importancia, como el área de tecnología e informática. En otras palabras, se identifica la mirada de un docente que reconoce la transversalidad académica como un elemento clave dentro del aprendizaje y, por lo mismo, su quehacer pedagógico se nutre desde la perspectiva de otras disciplinas, en la medida que exista un constante cuestionamiento frente a como innovar dentro del aula escolar.

En efecto, el aprendizaje abarca no solo las diversas áreas del conocimiento sino también un proceso transitorio en el cual el docente en los diversos niveles de escolaridad identifica aquellos acercamientos que se pueden lograr en el estudiante teniendo en cuenta su edad y año escolar.

La serie 4 permite ver una constante en la respuesta al afirmar que los new media deben utilizarse solo en básica secundaria. Este hallazgo está relacionado con la mirada de Prendes (2015) quien sostiene que, si bien es cierto se debe acudir a recursos tecnológicos para potenciar ambientes de aprendizaje y mejorar la calidad educativa, los docentes deben saber escoger qué tipo de recursos son utilizables y a qué nivel de escolaridad, esto con el fin de lograr experiencias de aprendizaje que fortalezcan no solo un plan de estudio, sino que se consoliden investigaciones que abran la posibilidad de un estado del arte en relación a esta temática.

Se identifica la existencia de un compromiso formativo por parte del docente hacia sus estudiantes y, por ende, hacia su área académica. Se habla de compromiso, pues en la medida que el docente oriente sus metodologías de enseñanza y utilice adecuadamente los recursos tecnológicos se puede lograr avances en el aprendizaje, así como una alta calidad educativa. Los anteriores hallazgos se relacionan con la serie 5, al evidenciarse una constante en la respuesta frente a la importancia de las tecnológicas y su relación con los new media. Para los docentes, la tecnología debe ser una aliada para innovar en su práctica educativa y saber utilizarla de tal manera que no se deje de lado la sensibilidad del estudiante y, por el contrario, se potencialicen sus habilidades, la capacidad de indagar procesos culturales, sociales y naturales, elementos que propone el Ministerio de Educación desde su documento de orientaciones pedagógicas para la asignatura de educación artística.

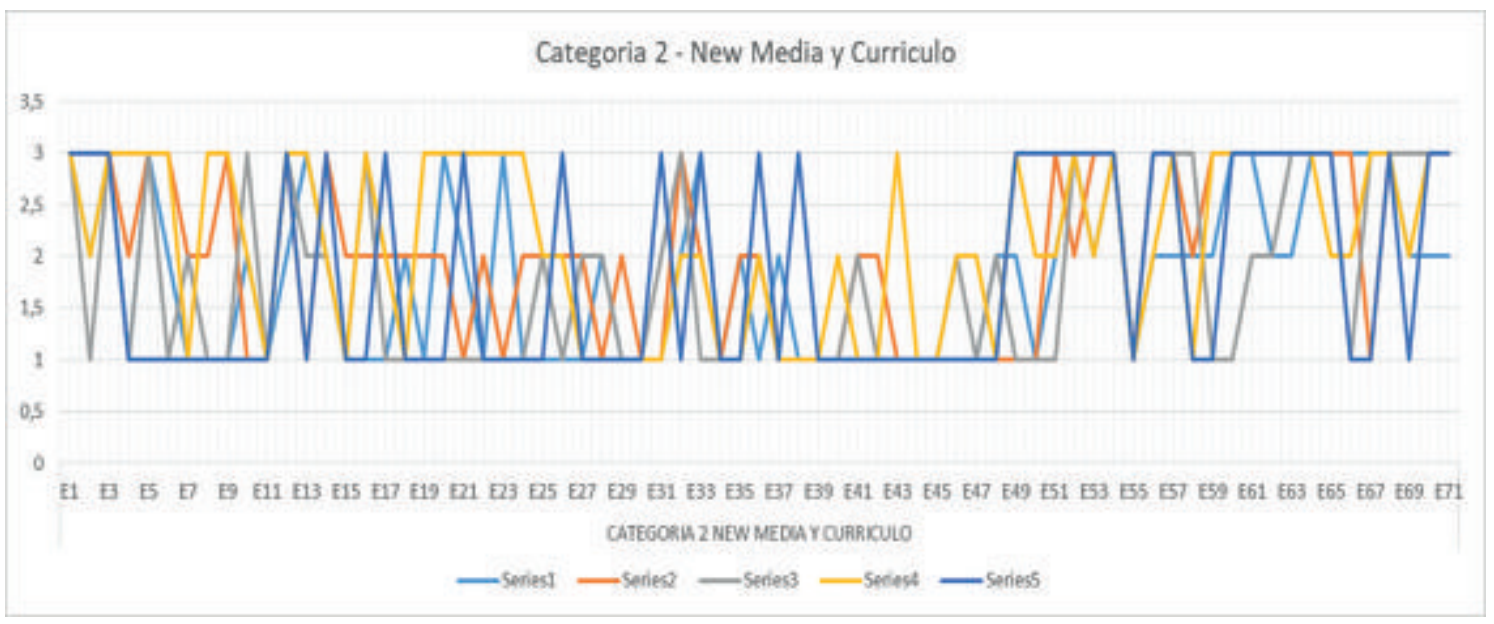

Figura 4. Relación entre new media y el currículo.

Fuente: elaboración propia. 
Tanto el currículo como el plan de estudio obedecen a parámetros institucionales que orientan el quehacer pedagógico. En ese sentido, debe existir una flexibilidad que le permita al docente enriquecer sus métodos de enseñanza desde diversas áreas, pero fortaleciendo procesos puntuales que para esta investigación están relacionados con el área de educación artística. Los hallazgos encontrados en la serie 1 reflejan la existencia de un conocimiento general en lo relacionado al currículo y un conocimiento más específico en lo relacionado al plan de estudios. Este último debe ser flexible y debe tener como propósito elementos claves para el proceso creativo como la sensibilidad y el pensamiento crítico, aspectos que hacen parte de la educación artística.

Tanto el currículo como el plan de estudios deben concebirse como herramientas fundamentales para que el docente pueda ejercer su labor pedagógica acorde con lo estipulado por el Ministerio de Educación. Desde esta postura, Jordan y Codana (2019) afirman que en la medida que los docentes sean apasionados por su labor pedagógica, se puede incidir en la mejora académica de los estudiantes. En el caso del quehacer pedagógico del docente, los autores sostienen que los docentes exitosos son aquellos que evidencian pasión en el desarrollo de sus ambientes de aprendizaje y se ve reflejado en los aprendizajes que obtienen los estudiantes, todo ello se logra desde la planeación y alineación con el currículo académico.

Tanto las TIC como el currículo exigen una constante retroalimentación que permita atender las demandas de un mundo globalizado, que obedece a un mismo propósito relacionado con educación de calidad. Lo arrojado en la serie 2, cuya pregunta estaba vinculada con tecnologías, evidencia que en su mayoría los docentes afirman que en el momento de su formación profesional vieron algunas materias cercanas al arte y la tecnología, pero con poca profundidad.

La serie 3, que refleja los resultados de la pregunta relacionada con la actualización en los planes de estudio, muestra que los docentes, en su gran mayoría, afirman que el plan de estudios debe permitir la creación de ambientes de aprendizajes contextualizados y logran la apropiación de medios digitales dentro de la formación profesional. En otras palabras, impera la necesidad de vincular la era digital a los procesos formativos y ejercer la profesión docente con herramientas que estén a la vanguardia de lo que demanda la sociedad. En esta perspectiva, Nieva y Martínez (2016) sostienen que la formación docente es fundamental en términos de calidad educativa que busca siempre aportar en lo cultural, lo tecnológico y lo humano. Debe ser un proceso continuo y reflexivo, ya que esto es lo que permite mejorar el quehacer pedagógico.

Con respecto a la serie 4 , tuvo porobjetivo identificar en el docente características relacionadas con la tecnología que apoyen la construcción del conocimiento, para lo cual se destacó el ambiente colaborativo con ambientes de aprendizaje que surjan dentro o fuera del aula escolar. Al respecto, Rodríguez y Espinoza (2017) afirman que para llegar al aprendizaje colaborativo se busca que el docente diseñe actividades mediadoras y orientadoras con el propósito de ser el promotor de nuevos ambientes de aprendizaje, para ello también es necesario que sus estudiantes compartan sus tareas, inquietudes y objetivos con el fin de consolidar metas comunes. En otras palabras, el trabajo colaborativo es parte fundamental para mejorar la calidad educativa.

Finalmente, la serie 5 permite identificar que para los docentes el pensamiento crítico resulta más relevante que la innovación y la investigación. Desde esta postura es necesario destacar lo aportes de Tamayo et ál. (2015), quienes afirman que teniendo en cuenta el tipo de educación colombiana, que hace énfasis en conceptos y teorías en las diversas áreas académicas, se hace necesario proponer nuevas metodologías de enseñanzas en las que el estudiante desarrolle dicho pensamiento desde el concepto adquirido. Es decir, el pensamiento crítico es de gran relevancia y puede ser fortalecido desde las nuevas tecnologías de la información y la comunicación. En definitiva, resulta necesario comprender que la calidad educativa se fortalece desde varias dimensiones que se potencializan en todas las áreas del conocimiento y que depende en gran medida de la pedagogía y didáctica del docente. 


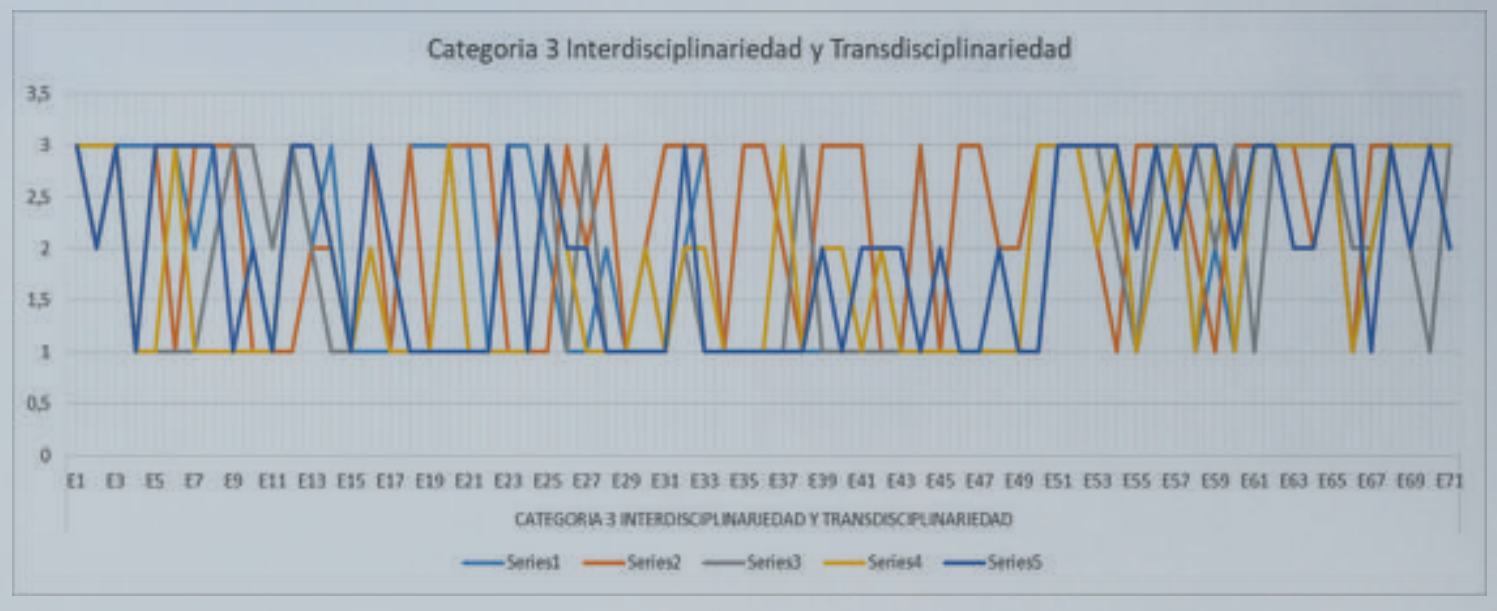

Figura 5. Interdisciplinariedad y educación artística.

Fuente: elaboración propia.

Así como las ciencias naturales o el español, la educación artística en Colombia es un área académica obligatoria dentro del plan de estudios. Su intensidad horaria es baja en comparación a otras asignaturas, como las matemáticas, que maneja una intensidad de 6 a 8 horas en la semana. A partir de ello, en los hallazgos encontrados en la serie 1, los docentes consideran dos puntos que vale la pena mencionar: el primero advierte que la asignatura es utilizada en su gran mayoría para eventos culturales y el segundo señala su insuficiente intensidad horaria. Los docentes coinciden en afirmar que es una intensidad horaria baja en relación a los beneficios y aportes que esta asignatura hace a otras áreas del conocimiento.

De acuerdo con el cuarto objetivo de desarrollo sostenible, que hace referencia a la educación de calidad en la agenda 2030 emitida por la Comisión Económica para América Latina y el Caribe (2019), la responsabilidad del sector educativo se encamina hacia brindar alternativas de aprendizaje permanente. Estas alternativas deben estar bajo modelos pedagógicos que contribuyan a la formación integral del estudiante con el fin de lograr una educación trasformadora, creativa y sostenible. Dicho lo anterior y a la luz de los hallazgos encontrados, se hace necesario replantear la intensidad horaria en las instituciones educativas con el fin de posibilitar más momentos pedagógicos en los cuales el estudiante potencialice sus habilidades, fortalezca sus procesos creativos y desarrolle el pensamiento crítico, dado que es un proceso necesario y según la perspectiva de Severino-González et ál. (2019) se podría entender como entornos de aprendizaje, pues gracias a ellos el estudiante tiene la posibilidad de interactuar, ejercicio fundamental para su formación integral.

Lo identificado en la serie 2 está relacionado con los lineamientos curriculares establecidos por el Ministerio de Educación Nacional y al respecto los docentes coinciden en afirmar que dichos lineamientos fueron diseñados para desarrollar la creatividad, pero están desactualizados. Lo anterior puede obedecer al auge de las nuevas tecnologías que apuntalan la educación artística y le dan la posibilidad al docente de tener nuevas herramientas didácticas para desarrollar su quehacer pedagógico. Estas herramientas hacen referencia a los new media que permiten desarrollar procesos creativos y aportar a un aprendizaje significativo en el estudiante. Un ejemplo de ello es la realidad aumentada, una tecnología que apoyada en dispositivos electrónicos permite estar en tiempo real en una situación determinada. Según las investigaciones desarrolladas por Cabero-Almenara y Pérez (2018), este tipo de tecnología puede lograr experiencias sensoriales en los estudiantes y en este sentido sus aprendizajes serán más efectivos. 
La interdisciplinariedad siempre será un elemento clave para una educación de calidad. Todas las áreas del conocimiento abordadas desde ambientes de aprendizaje innovadores logran en los estudiantes aprendizajes significativos y en el docente la evolución en su quehacer pedagógico. Sclater y Lally (2018) señalan al respecto que la interdisciplinariedad en procesos pedagógicos relacionados con la educación artística es un elemento fundamental, ya que da la posibilidad de crear ambientes de aprendizaje creativos, con el fin de dar paso a nuevas formas de educación en las que se vinculen prácticas creativas e innovadoras, como el videoarte, el performance o la fotografía.

Dicho lo anterior, los resultados arrojados en la serie 3 permiten identificar que, para los docentes, la educación artística debe formar parte de la ciencia y la tecnología, como también estar a la vanguardia de procesos investigativos. Este hallazgo comprueba la necesidad de desarrollar investigaciones relacionadas con esta área del conocimiento, pues es allí donde nace la interdisciplinariedad. Si bien es cierto que todas las áreas del conocimiento son importantes dentro del proceso formativo del estudiante, Sclater y Lally (2018) resaltan la importancia de este elemento dentro del proceso formativo al ser una posibilidad que se le da al estudiante de explorar competencias que aportan a otras áreas académicas, conocer nuevos entornos de aprendizajes que son trasversales y de gran potencial para desarrollar por parte del docente.

Ahora bien, mediante los resultados de la serie 4 se logra identificar una responsabilidad frente a la labor pedagógica y su papel en la interdisciplinariedad. Para los docentes es importante explorar recursos didácticos, como también ir de la mano con la tecnología. Se refleja un complemento que aporta en las metodologías de enseñanza abordando diversas áreas del conocimiento.

Finalmente, la serie 5 tuvo como propósito conocer cómo fortalecer el aprendizaje de un estudiante desde la mirada del docente. En efecto, los datos arrojados concluyen que el estudiante parte de una experiencia previa desde el dialogo y la reflexión. Esto permite corroborar la postura de Rodríguez y Espinoza (2017) con relación al aprendizaje colaborativo.

\section{Interpretación de los datos a la luz de las categorías}

Categoría 1. New media

New media no es un concepto reciente en el contexto de la educación artística, en los hallazgos identificados en la gráfica se observa un conocimiento general del concepto. En la actualidad el término new media es utilizado en todas las áreas del conocimiento y vinculado de manera correcta con la tecnología; sin embargo, es necesario que el docente fortalezca su comprensión de manera implícita vislumbrando que el arte de los nuevos medios implica la incorporación de la tecnología al arte.

Ahora bien, el docente de las áreas de tecnología e informática y de educación artística bosqueja mapas mentales en el intento de consolidar la unión de estos elementos desde la experiencia de su título base sin lograr fundamentar dicha relación, no por la existencia de un desconocimiento, sino porque en la zona de confort en la que se encuentra enfoca su práctica pedagógica a la repetición de saberes y aplicación de los mismos y no a la incorporación de nuevos elementos.

Aunque la gráfica señala que el docente no desconoce la existencia de los new media, incluso en algunas constantes lineales de las series se identifica la aplicación correcta de elementos de este ámbito, el supuesto conocimiento de esta categoría se da principalmente porque en el argot popular del medio se vincula únicamente a escenarios como Ambientes Virtuales de Aprendizaje, Entornos Virtuales, web 2.0, entre otros, dejando de lado los cimientos de gran relevancia en el contexto educativo como lo es la educación artística.

Categoría 2. New media y currículo

En esta categoría se decanta aún más la información conducente a identificar y consolidar las falencias de forma y de fondo para comprender

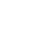


por qué los docentes que desarrollan su práctica pedagógica en el área de artes no tienen una verdadera aprehensión de los new media. Es por ello que la unión literal new media y currículo no existe, es decir, un eje articulador que gire en torno a new media específicamente. Al identificar este hallazgo urge la actualización de los diseños curriculares de las instituciones de educación superior que ofertan licenciaturas y carreras en áreas afines.

Al realizarse dicha actualización, el docente tendrá alternativas de solución que le permitan desarrollar su ejercicio pedagógico de acuerdo al contexto de la población estudiantil. Cada institución educativa recibe al inicio del año escolar estudiantes con características familiares, culturales y sociales muy diferentes y en ese sentido los ambientes de aprendizajes no deberían ser los mismos. El docente debe recurrir a la flexibilización en búsqueda no solo de lograr aprendizajes en sus estudiantes, sino también de dar cumplimiento a las políticas educativas establecidas por el Estado, que en muchas ocasiones no corresponden con la realidad que se vive en el aula escolar.

La relación entre new media y currículo se convirtió en la concatenación de la tecnología y el arte, así lo demuestra la población estudio en el caso de esta investigación. La trazabilidad de las respuestas manifiesta que para ellos mientras que el currículo evidencie asignaturas con el mínimo de vinculación de las tecnologías, se da por hecho que el currículo cumple con la necesidad de formación.

\section{Categoría 3. Interdisciplinariedad y transdisciplinariedad}

La interdisciplinariedad y la transdisciplinariedad son elementos fundamentales para dar cumplimiento a los objetivos del desarrollo sostenible. Unir el arte a la tecnología significa, por tanto, lograr que los estudiantes no solo fortalezcan su creatividad, sino que también fortalezcan conceptos de otras áreas del conocimiento que pueden estar inmersas en la educación artística. En lo que respecta a los docentes, esta asignatura también puede vincularse con elementos de la ciencia y la tecnología y, de esta manera, se pondría de manifiesto desde el ámbito de la investigación científica cómo la transversalidad aporta en el aula escolar promoviendo ambientes de aprendizajes enriquecedores que propicien iniciativas como los semilleros de investigación. En este punto se corroboraría la mirada de González (2014), quien afirma que la interdisciplinariedad y la transdisciplinariedad son complementos integrales en la calidad educativa y más específicamente en lo relacionado al ámbito de las artes.

En la lectura de la gráfica es identificable que en las instituciones educativas la interdisciplinariedad se da cuando es necesario efectuar eventos y es una realidad irrefutable, lo que no se concibe es la educación artística como profundización o eje central de los proyectos educativos institucionales. La ley general de Educación brinda los parámetros para el diseño de planes de estudio institucionales, mientras que el Ministerio de Educación y la Comisión Nacional de Acreditación hacen lo propio para el diseño de pénsum. Dado el análisis realizado en este trabajo, es posible comenzar a identificar los desatinos cometidos, que al ser subsanados logren que el arte sea referente para la transversalización de las áreas. 
Una de las lecturas más claras de la categoría es la visualización de los picos en los extremos de las series, brindan fundamento para la aseveración que los docentes que desarrollan su labor pedagógica en áreas afines al arte no es clara la concepción de arte como una asignatura interdisciplinar, en cambio se tiende hacia subjetividades respecto a la importancia que cada individuo le da al desarrollo de su área lo que se ve reflejado en las respuestas dadas por los docentes.

La interdisciplinariedad y la transversalidad debe ser el centro del proceso de formación docente, por eso resulta pertinente y de gran valor pedagógico lograr la equidad, vinculando todas las áreas del conocimiento en relación a los new media, ya que esta cuenta con los elementos suficientes para cimentar el diseño de un espiral ascendente en lo que respecta a la formación docente.

\section{Conclusiones}

La calidad educativa debe responder a las demandas de cada país teniendo en cuenta las características de su población, en concordancia con lo señalado por el documento Agenda 2030 y los Objetivos de Desarrollo Sostenible en su cuarto objetivo "Garantizar una educación inclusiva y equitativa de calidad y promover oportunidades de aprendizaje permanente para todos" (Cepal, 2019, p. 27). Desde esa postura, el estudio arrojó que en Colombia, para el caso específico en la ciudad de Bogotá, los docentes tienen conocimiento general acerca de los new media; sin embargo, en aras de potenciar prácticas educativas innovadoras en el área de educación artística, urge una actualización en procesos formativos que oferten las instituciones de educación superior en el que incluyan dentro de sus planes de estudio los new media y todo a lo que ellos se refiere, En ese sentido, cuando el docente se vea enfrentado a sus estudiantes tendrá las herramientas necesarias para innovar en su didáctica escolar en la medida que vincule procesos artísticos desarrollados a partir de la ciencia y la tecnología. En la actualidad, el docente se ve enfrentado a una situación mundial que lo obliga a buscar nuevos recursos digitales e innovar en sus metodologías de enseñanza que le permitan lograr en el estudiante momentos de creación a partir de ejercicios con ayuda de la tecnología.

Es necesario que entidades como la Secretaria de Educación junto con el Ministerio de Educación Nacional aseguren la presencia de equipo docente de educación artística tanto para los niveles iniciales, en los que se dan los primeros acercamientos al arte y la tecnología, como en niveles de educación secundaria, para que no se interrumpan o afecten los procesos creativos. Los docentes coinciden en afirmar que los new media pueden aportar al desarrollo de la creatividad del estudiante. No obstante, se apoyan en los lineamientos de la educación artística y las orientaciones pedagogías de dicha área y encuentran que estas requieren una actualización en la que se incluyan los new media como parte del fortalecimiento del proceso creativo, sensitivo y estético del estudiante. 
Si bien es cierto que el arte al unirse con la tecnología le da la oportunidad al estudiante para que explore y comprenda los beneficios que están relacionados con sus procesos creativos y su pensamiento crítico, la asignatura de educación artística debe permitirle al estudiante el fortalecimiento de su sensibilidad y apreciación estética, así como también la capacidad de expresar desde lo pictórico, lo musical o lo visual una postura frente a un tema determinado. En definitiva, los diferentes lenguajes del arte son canales de comunicación frente a la sociedad, y si se incluyen los new media como material de enseñanza en la educación artística, podrían surgir innovadoras propuestas en los estudiantes.

$\mathrm{Al}$ ser una asignatura innovadora, dejará de ser solo un elemento para ser mostrado en actos culturales y trascenderá para convertirse en la oportunidad para sembrar talentos que se vean reflejados a futuro en escenarios de gran importancia para el sector cultural, como el salón de arte y tecnología, Artbo o Barcu, espacios que se han posicionado en el ámbito artístico de la ciudad de Bogotá. El plan de estudios y el currículo que desarrolla el docente dentro de su quehacer pedagógico debe estar en constante retroalimentación, ya que es desde allí donde se orientan el diseño de cada una de las clases y, en ese sentido, se adquiere un compromiso pedagógico y social si lo que se pretende es apuntar a una educación de calidad.

Según las orientaciones pedagógicas para la educación artística direccionadas por el Ministerio de Educación Nacional (2010), los estudiantes poseen varios tipos de sensibilidades, para esta investigación se destacan dos: la visual como la relación sintética de las cosas que le permite al estudiante tener más herramientas para comprender el mundo, por ende un ejercicio artístico; la sensibilidad auditiva, producida por la música o simplemente por los ruidos que surgen de la cotidianidad, por ello urge la necesidad de actualizar estos documentos de apoyo con el fin de proponer lineamientos interdisciplinares y transversales que surjan a partir de esta asignatura.

Desde esta postura, si un estudiante tiene acceso a propuestas que estén relacionadas con el arte y la tecnología esto repercutirá en su proceso creativo, redescubrirá un contexto en el cual la atención, la concentración y la escucha son fundamentales. Para llegar a esto es necesario que el docente revise, replantee y actualice sus planes de estudio para poder desarrollar métodos de enseñanza que fortalezcan lo auditivo y lo visual promoviendo aprendizajes innovadores que aporten a una formación integral.
En Colombia las aprobaciones de los registros calificados de los programas académicos de las universidades se expiden con una vigencia de siete años para su funcionamiento. De esta manera, se esperan siete años a que los establecimientos de educación superior revisan a profundidad los planes educativos que ofertan, únicamente con el objetivo de renovar la aprobación del registro. Y aunque este proceso de revisión de una u otra forma se convierte en un ejercicio de auto evaluación en el que se identifica lo que se esperaba desde el inicio de la oferta educativa hasta la finalización de las cohortes del programa, no existe finalmente un enriquecimiento ni del pénsum ni del currículo de una manera constante, crítica y constructiva.

Adicionalmente, se tiene que cuando el docente inicia su ejercicio profesional en las instituciones educativas de niveles de primaria y secundaria, bien sean públicas o privadas, se encuentra que en muchas ocasiones estos espacios que los reciben tienen diseños curriculares más contemporáneos, dado que la evaluación de los currículos de estas se realiza de manera anual, y logra incorporar a las áreas de aprendizaje nuevas didácticas. Esto conlleva un conflicto para el docente, ya que si no cuenta con una formación pertinente en este contexto puede generarse un sentimiento de ignorancia que lo lleve a pensar "lo que aprendí en la universidad no me sirvió para nada”.

Es necesario que en la formación docente existan líneas claras y bien constituidas desde el primer semestre hasta el final del ciclo en temas de tecnologías educativas innovadoras y que se aborden de manera fáctica, es decir, no solo llenar de información a los estudiantes sino lograr evidenciar desde el inicio la aplicabilidad de la tecnología a problemas reales de aprendizaje de la población en atención a sus características particulares.

Generalmente existen proyectos innovadores para aplicación de la tecnología a problemáticas, pero usualmente dichas iniciativas solo se construyen a modo de prototipos o ideas de solución para participar en congresos, competencias o ganar becas y no avanzan de ese punto. Es por ello que la formación docente debe ser in situ, resaltar problemáticas reales con características diversas de la población estudiantil de tipo cognitivo, motriz, de desarrollo social, debido a que es en estos escenarios en donde se pueden aplicar los desarrollos tecnológicos ya existentes para evaluar su viabilidad o dirigir su reestructuración. 
$\mathrm{Al}$ individuo que estudia para docente lo caracteriza la vocación a servir como puente del aprendizaje. Esa particularidad es el fundamento para llevarlo a campo desde el inicio de su proceso de formación para que conviva con la comunidad y construya soluciones reales que se constituyan en una contribución efectiva a través de la transdisciplinariedad.

\section{Referencias}

Arévalo, M., Gamboa, A. y Hernández, C. (2016). Políticas y programas del sistema educativo colombiano como marco para la articulación de las TIC. Revista Aletheia. 8(1), 12-31. https://doi. org/10.11600/21450366.8.1aletheia.12.31

Cabero-Almenara, J. y Pérez, J. L. (2018). Validación del modelo TAm de adopción de la Realidad Aumentada mediante educaciones estructurales. Estudios sobre educación, 34, 129-153. https://doi. org/10.15581/004.34.129-153

Caeiro, M. y Muñiz, A. M. (2019). La cognición expresiva como una experiencia de relación de arte y ciencia en la educación preuniversitaria. Artnodes, (24), 142-154. https://doi.org/10.7238/a.v0i24.3259

Comisión Económica para América Latina y el Caribe (Cepal). (2019). La Agenda 2030 y los Objetivos de Desarrollo Sostenible: una oportunidad para América Latina y el Caribe. Objetivos, metas e indicadores mundiales. https://www.cepal.org/es/publicaciones/40155-la-agenda-2030-objetivos-desarrollo-sostenible-oportunidad-america-latina-caribe

De Camilloni, A. (2007). Didáctica general y didácticas específicas. En A. de Camilloni, E. Cols, L. Basabe, y S. Feeney, El saber dídáctico (pp. 23-38). Paidos.

Díaz-Barriga, A. (2011). Competencias en educación. Corrientes de pensamiento e implicaciones para el currículo y el trabajo en el aula. Revista iberoamericana de educación superior, 5(2), 3-24. http://www. scielo.org.mx/scielo.php?script=sci_arttext\&pi$\mathrm{d}=$ S2007-28722011000300001\&lng=es\&tlng=es

Edelstein, G. (2015). La enseñanza en la formación para la práctica. EFI Educación, Formación, Investigación. 1(1), 1-11. http://ppct.caicyt.gov.ar/index.php/efi/article/ view/6219/5662

Fernández, C. (2014). Presentación Monográfico Media Art. ICONO14, 12(2), 1-8. https://doi.org/10.7195/ri14. v12i 2.734
Gombrich, C. (2018). Implementing Interdisciplinary Curricula. Some Philosophical and Practical Remarks. European Review, 26, S41-S54. https://doi.org/10.1017/ S1062798718000315

Gómez, M. (2015). Introducción a la metodología de la investigación científica. Editorial Brujas

Gómez-Redondo, C., Fontal, O. e Ibáñez-Etxeberria, A. (2016). Procesos de patrimonialización e identización patrimonial con uso de TIC en torno al arte contemporáneo. Artnodes, (17), 53-63. http://doi.org/10.7238/a. v0i17.2827

González-Aguilar, H. (2014). Inter y transdisciplinariedad: Una reflexión en la educación. Paideia xxI, 4(5), 95-103. https://doi.org/10.31381/paideia.v4i5.911

González, R. (2016). El arte y su educación en la era de la hipermediación digital. Artnodes, (17), 43-51.

Hernández-Sampieri, R. y Mendoza-Torres, C. (2018). Metodología de la investigación-Las rutas cuantitativa, cualitativa y mixta. McGraw-Hill Interamericana.

Jordan, J. y Codana, A. (2019). La influencia del profesor apasionado en la mejora académica y el desarrollo personal de sus alumnos. Estudios sobres educación, 36 31-51. https://doi.org/10.15581/004.36.31-51

Llano-Arana, L., Gutiérrez-Escobar, M., Stable-Rodríguez, A., Núñez-Martínez, M., Masó-Rivero, R., y RojasRivero, B. (2016). La interdisciplinariedad: una necesidad contemporánea para favorecer el proceso de enseñanza aprendizaje. MediSur, 14(3), 320-327. http:// scielo.sld.cu/scielo.php?script=sci_arttext\&pi$\mathrm{d}=$ S1727-897X2016000300015\&lng=es\&tlng=es

Martín, D. R. (2015). La formación docente universitaria en Cuba: sus fundamentos desde una perspectiva desarrolladora del aprendizaje y la enseñanza. Estudios Pedagógicos, 41(1), 337-349. https://doi.org/10.4067/ S0718-07052015000100020

Ministerio de Educación Nacional. (s.f.). Definición de currículo. Consultado el 17 de febrero de 2020. https://www. mineducacion.gov.co/1621/article-79413.html

Ministerio de Educación Nacional. (2010). Orientaciones Pedagógicas para la Educación Artística en Básica y Media. Documento No 16. https://www.mineducacion. gov.co/1621/articles-241907_archivo_pdf_evaluacion.pdf

Ministerio de Cultura. (2018.). Educación Artística. https:// mincultura.gov.co/areas/artes/educacion-artistica/ Paginas/default.aspx 
Mousalli-Kayat, G. (2015). Métodos y diseños de investigación cuantitativa. Mérida

Murillo, A., Riaño, M. y Berbel, N. (2019). El aula como caja de resonancia para la creación sonora: nuevas arquitecturas y herramientas tecnológicas para acercar el arte sonoro al ámbito educativo. Revista Electrónica de LEEME, (43), 1-18. https://doi. org/10.7203/LEEME.43.14007

Nieva, J. A. y Martínez, O. (2016). Una nueva mirada sobre la formación docente. Universidad y Sociedad, 8(4), 14-21.

Prendes, C. (2015). Realidad aumentada y educación: análisis de experiencias prácticas. Pixel-Bit. Revista de Medios y Educación, (46), 187-203. https://doi. org/10.12795/pixelbit.2015.i46.12

Rocha, R. (2016). El modelo educativo basado en competencias para la enseñanza del arte. Educere, 20(66), 215-224.

Rodríguez, R. y Espinoza, L. (2017) Trabajo colaborativo y estrategias de aprendizaje en entornos virtuales en jóvenes universitarios. RIDE. Revista Iberoamericana para la Investigación y desarrollo Educativo, 7(14), 86-109. https://doi.org/10.23913/ride.v7i14.274

Sclater, M. y Lally, V. (2018). Interdisciplinarity and technology-enhanced learning: Reflections from art and design and educational perspectives. Research in Comparative and International Education, 13(1), 46-69. https://doi.org/10.1177/1745499918768111
Severino-González, P., Martín-Friorino, V. y GonzálezSoto, N. (2019). Responsabilidad social. De la toma de decisiones a la educación del carácter: percepciones de docentes y no docentes de un establecimiento educacional chileno. Estudios sobre educación, 37, 69-90. https://doi. org/10.15581/004.37.69-90

Tamayo, O. E., Zona, R. y Loaiza, Y. E. (2015). El pensamiento crítico en la educación. Algunas categorías centrales en su estudio. Revista Latinoamericana de Estudios Educativos, 11(2), 111-133.

Torres-Cañizález, P. C. y Cobo-Beltrán, J. K. (2017). Tecnología educativa y su papel en el logro de los fines de la educación. Educere, 21(68), 31-40. https:// www.redalyc.org/articulo.oa?id=356/35652744004

Unesco. (2016). Directrices Operativas para la aplicación de la Convención para la Salvaguardia del Patrimonio Cultural Inmaterial. Unesco. https://ich.unesco.org/ es/directrices

Xu, B., Li, X., Liang, H. y Li, Y. (2019). Research on professional talent training technology based on multimedia remote image analysis. EURASIP Journal on Image and Video, 39 (2019). https://doi. org/10.1186/s13640-019-0437

Zabalza-Beraza, M. A. (2012). Las competencias en la formación del profesorado de la teoría a las propuestas prácticas. Tendencias pedagógicas, 20, 5-32. https://dialnet.unirioja.es/servlet/ articulo? codigo $=4105027$

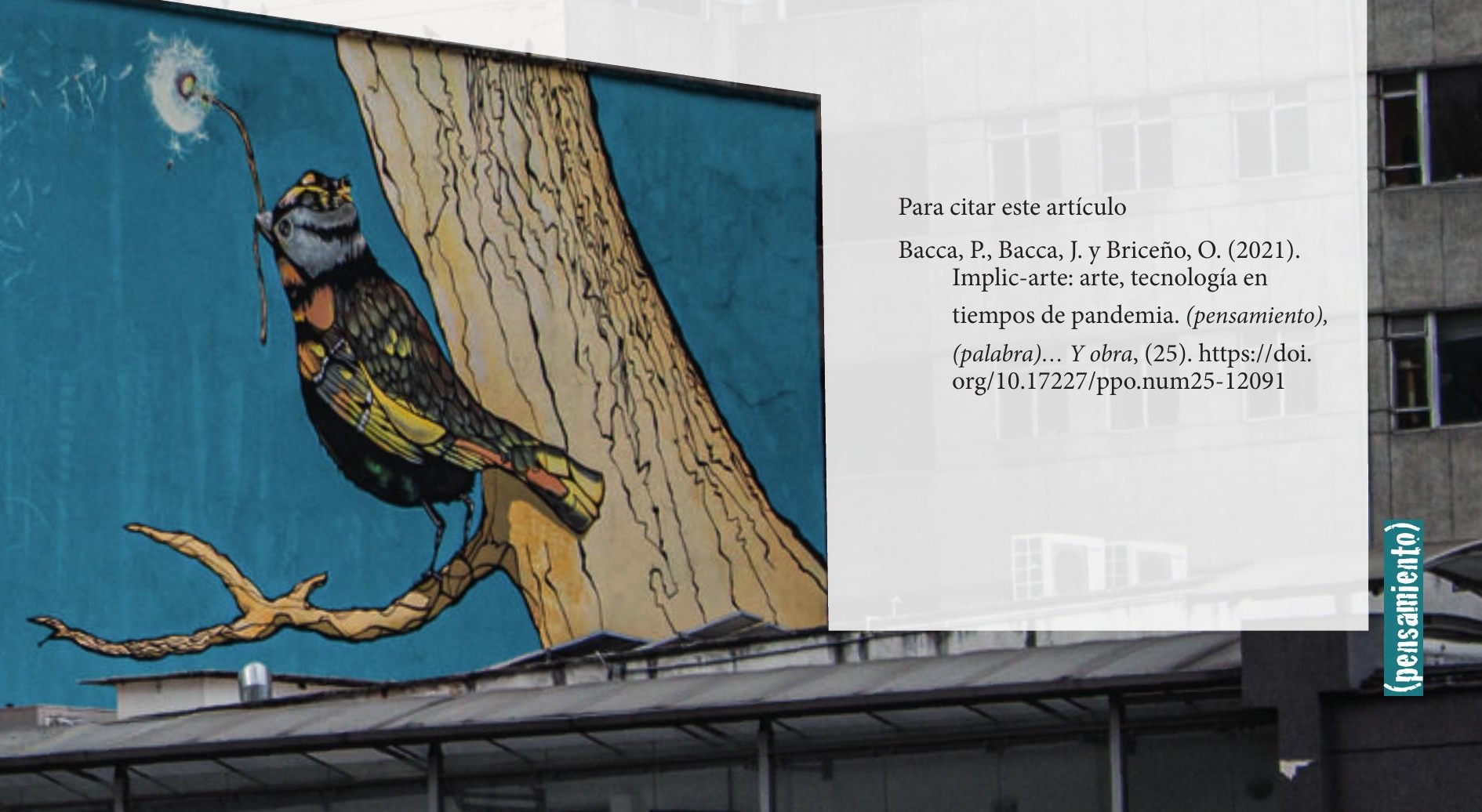

